
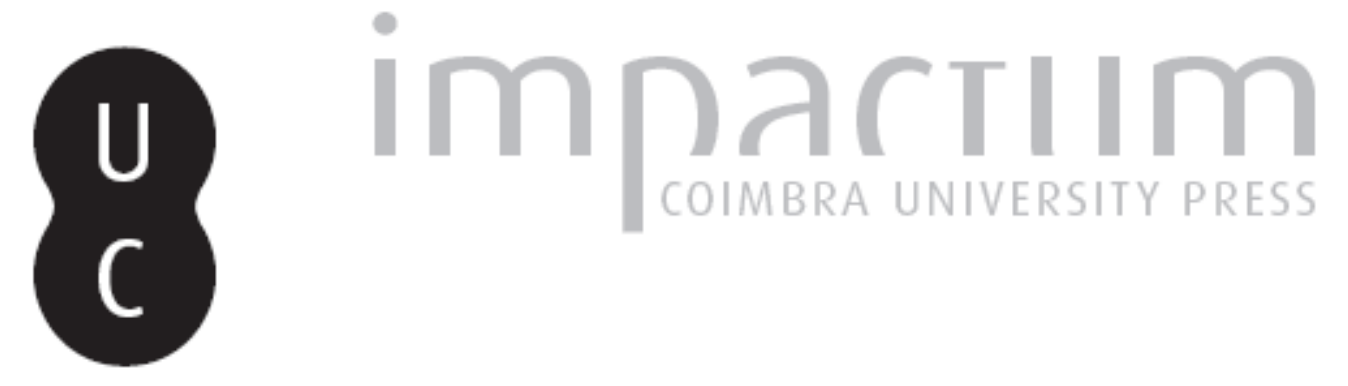

\title{
Zaha Hadid: a importância da forma
}
Autor(es):
Pimentel, André; Ferreira, João; Silva, Luis; Milheiro, Regina; Alves, Silvio

Publicado por: Editorial do Departamento de Arquitectura

URL persistente:

URI:http://hdl.handle.net/10316.2/37215

DOI:

DOI:http://dx.doi.org/10.14195/1647-8681_1_13

Accessed : $\quad$ 26-Apr-2023 10:36:08

A navegação consulta e descarregamento dos títulos inseridos nas Bibliotecas Digitais UC Digitalis, UC Pombalina e UC Impactum, pressupõem a aceitação plena e sem reservas dos Termos e Condições de Uso destas Bibliotecas Digitais, disponíveis em https://digitalis.uc.pt/pt-pt/termos.

Conforme exposto nos referidos Termos e Condições de Uso, o descarregamento de títulos de acesso restrito requer uma licença válida de autorização devendo o utilizador aceder ao(s) documento(s) a partir de um endereço de IP da instituição detentora da supramencionada licença.

Ao utilizador é apenas permitido o descarregamento para uso pessoal, pelo que o emprego do(s) título(s) descarregado(s) para outro fim, designadamente comercial, carece de autorização do respetivo autor ou editor da obra.

Na medida em que todas as obras da UC Digitalis se encontram protegidas pelo Código do Direito de Autor e Direitos Conexos e demais legislação aplicável, toda a cópia, parcial ou total, deste documento, nos casos em que é legalmente admitida, deverá conter ou fazer-se acompanhar por este aviso.

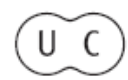




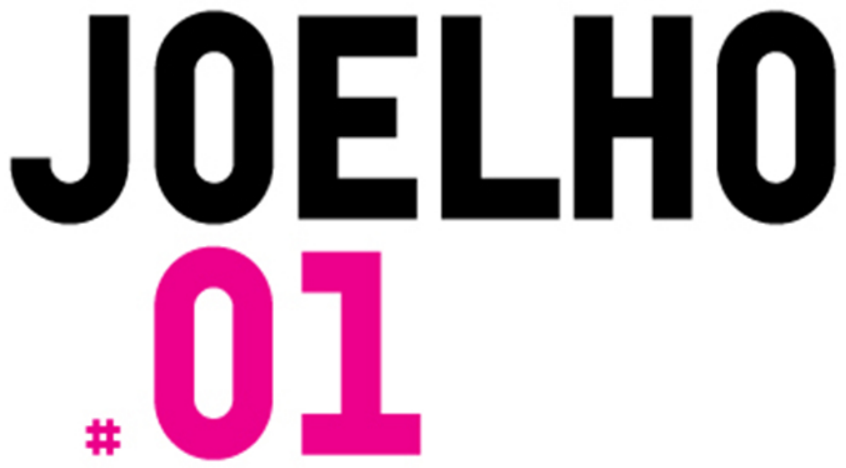

\section{MULHERES NA ARQUITECTURA}

Jorge Figueira

Coordenação

Silvana Rubino

Carla Lopes

Liliana Carvalho

Joana Bem-Haja

Filipa Cabrita

Inês Antunes

Telma Silva

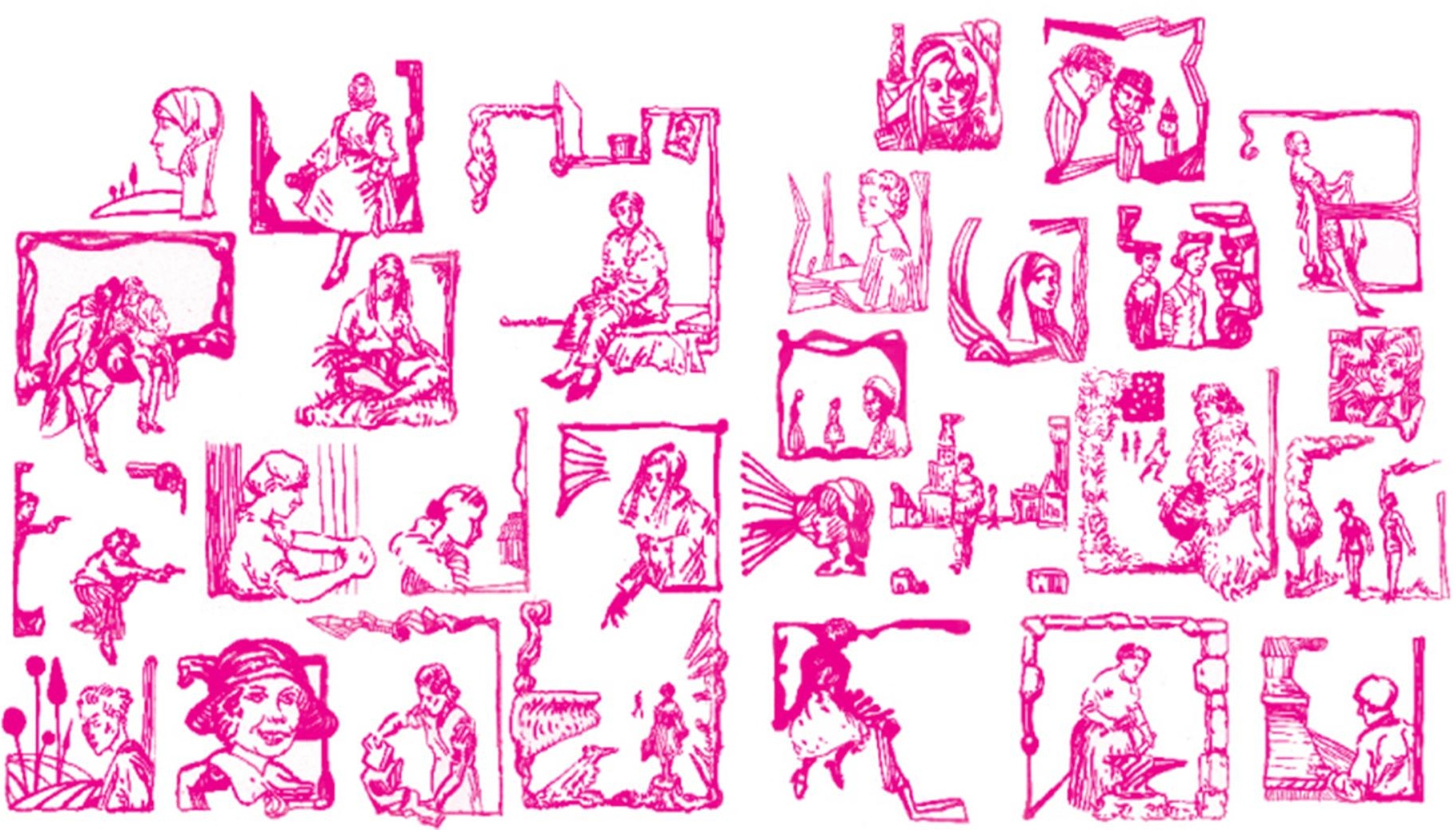


1950

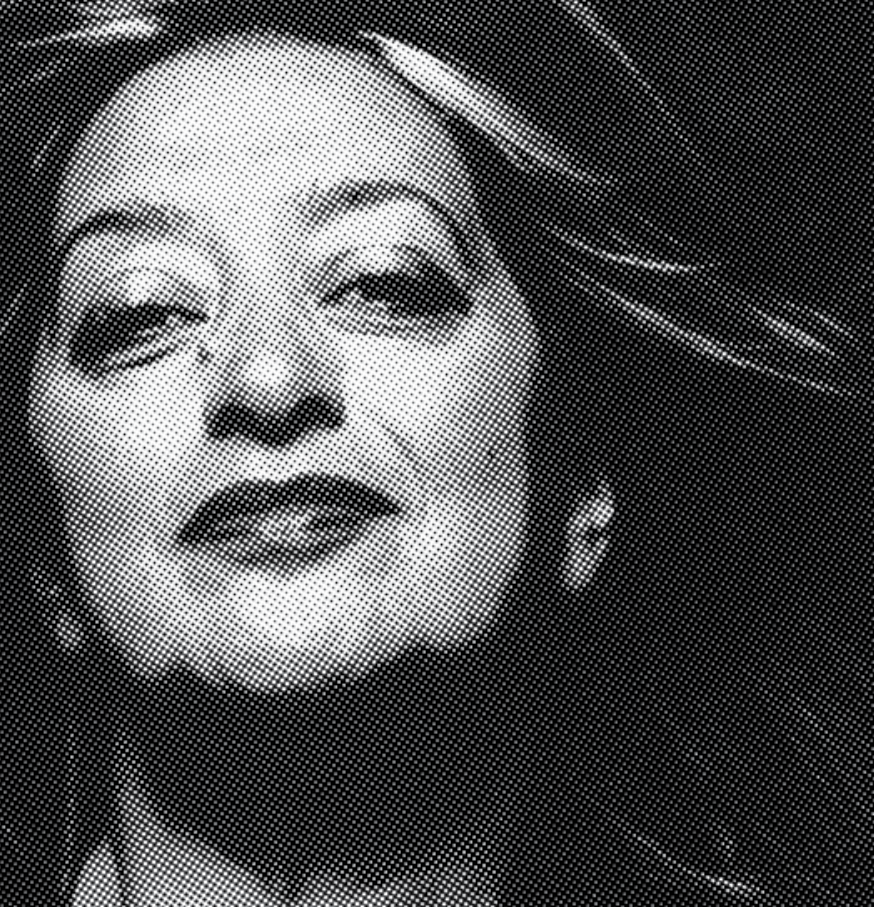




\section{Zaha Hadid}

\section{A importância da forma}

Nota biográfica:

Zaha Hadid nasceu em 1950, em Bagdad, Iraque. Depois de se formar em matemática na Universidade Americana de Beirute, inscreveu-se em 1972 na Architectural Association, em Londres. Formou-se em 1977 e a convite do seu antigo professor Rem Koolhaas, passa a integrar o Office for Metropolitan Architecture, onde permanece por pouco tempo. Em I983, a projecção internacional surge com o primeiro lugar no concurso para o The Peak Club, em Hong Kong. Em 2004, Zaha Hadid foi a primeira mulher premiada com o Pritzker. 

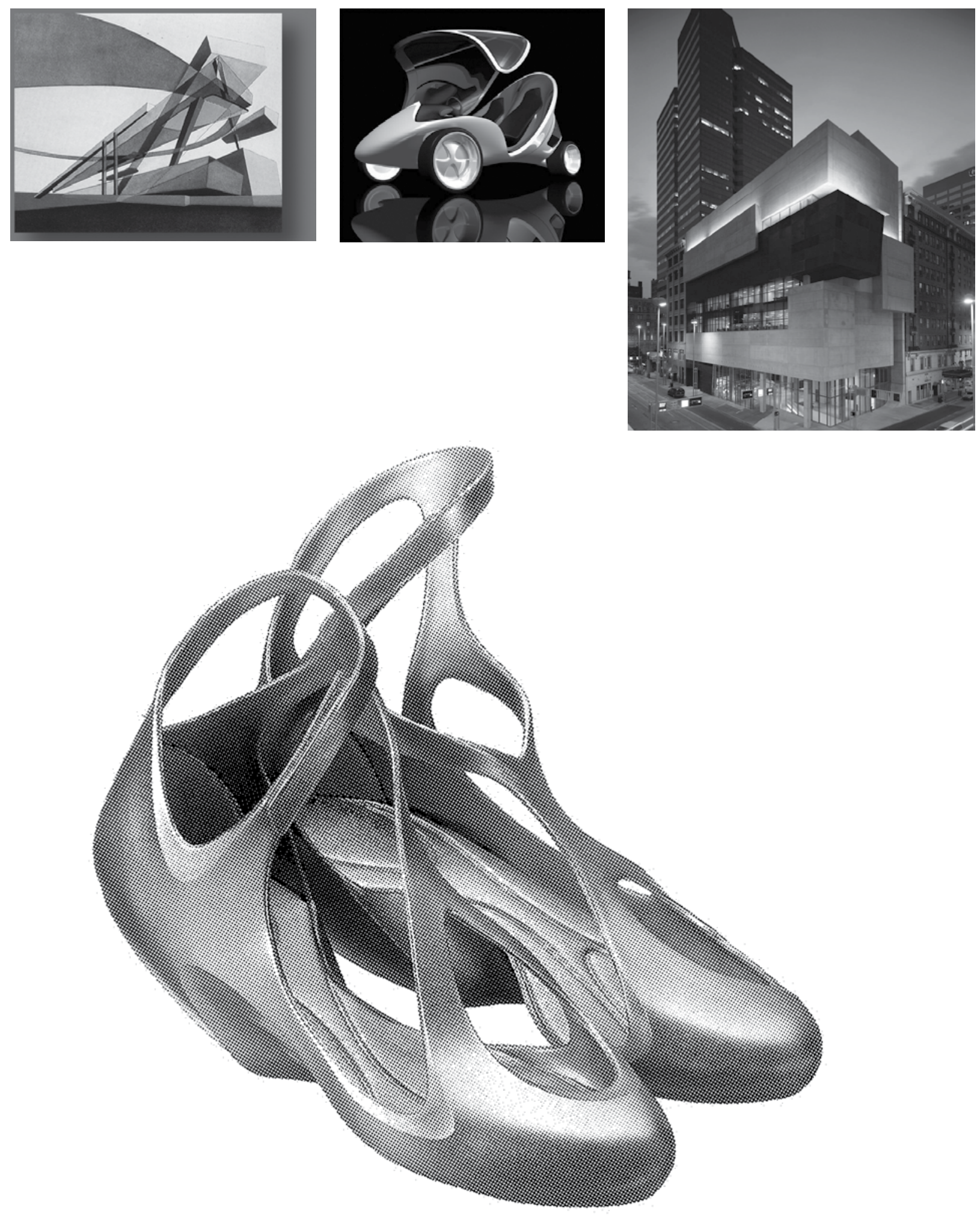
Perfil:

Zaha Hadid é um dos testemunhos correntes mais importante do contributo das mulheres para a arquitectura. Tendo em conta a competição exacerbada de um mercado de trabalho que tende constantemente a ser racial e sexualmente discriminatório, Zaha Hadid é já historicamente um dos maiores contributos no sentido de reconhecimento do trabalho das mulheres na arquitectura. A sua visão inovadora está presente nos seus projectos não construídos, desde que abriu o seu atelier em I980, mas também na contribuição académica em várias instituições. Actualmente é professora na Universidade de Artes Aplicadas, em Viena, Áustria.

$\mathrm{O}$ seu trabalho expande e intensifica as relações com a paisagem existente, procurando atingir uma estética de carácter visionário, que remete no entanto para referências da vanguarda do início do século $\mathrm{xx}$, em particular, o construtivismo russo. O seu trabalho de licenciatura, um Hotel na Hungerford Bridge chamava-se Malevich's Tectonik em referência ao artista russo.

Depois de uma fase em que os seus projectos não eram construídos, algumas das suas obras foram concluídas, com entusiasmo, em particular, o Contemporary Arts Centre em Cincinnati, EUA (2004).

Nas obras de Zaha Hadid, o carácter misterioso, complexo, sinuoso, estranho, dos espaços é um objectivo. E não se restringe à escala da arquitectura, a sua impressão percorre outros campos artísticos: design de interiores, mobiliário, equipamento, iluminação, veículos motorizados, design de moda. Observando algumas das suas peças de design e ampliando a sua escala na nossa imaginação, somos levados até aos seus edifícios. Sempre com o mesmo desenho, numa "escala futurista" que lembra naves espaciais de um futuro remoto. Ao longo do seu percurso, Zaha Hadid procura tocar nos limites da arquitectura e do design. Expandindo a imaginação e intensificando as paisagens existentes.
Fontes das imagens: http://forademoda.files.wordpress. com/2008/03/zaha_hadid_2.jpg

-

http://www.square-mag.co.uk/ wp-content/uploads/2006/12/ Zaha_Hadid_bucket.jpg

-

http://static.dezeen.com/ uploads/2007/07/painting_new_ tyres2.jpg

http://squadblog.files.wordpress. com/2009/03/zahashoesredblack.jpg

http://www.flickr.com/ photos/13173266@ N00/321783444/

http://www.bluffton.edu/ sullivanm/ ohio/cincy/hadid/side.jpg

Elementos do grupo: André Pimentel João Ferreira Luis Silva Regina Milheiro Silvio Alves 